\title{
Thermal and dynamic mechanical properties of polyethylene glycol/quartzcomposites for phase change materials
}

\begin{abstract}
Polyethylene glycol (PEG)/quartz (denoted as BP/Q) composites have been investigated as candidates of phase change materials (PCMs) due to their thermomechanical properties around the glass transition temperature as well as thermal properties between 30 and $600{ }^{\circ} \mathrm{C}$. Quartz (q-SiO2) powders were extracted from local sand in Tanah Laut, Pelaihari, South Kalimantan, Indonesia. The composites were prepared by dispersing q-SiO2 powders in the PEG matrix followed by the wet mixing process. The thermal properties of the composites were characterized using differential scanning calorimetry (DSC) and thermogravimetric analysis (TGA), while the thermomechanical properties were examined using a dynamic mechanical analyzer (DMA) in a three-point bending mode around the PEG glass transition temperature range $\left(-100-50^{\circ} \mathrm{C}\right)$. The morphology and interface bonding were investigated using scanning electron microscopy (SEM) and transmission electron microscopy (TEM). From the DSC measurement, the endothermic peak of the composites showed a shift of approximately $7-12{ }^{\circ} \mathrm{C}$ toward higher temperatures than that of the pure polymer. The melting enthalpy values $(\Delta \mathrm{Hm})$ of the $\mathrm{BP} / \mathrm{Q}$ composites covered the required PCM application range, that is, between 139 and $182 \mathrm{~J} / \mathrm{g}$. The TGA of the composites showed that thermal degradation occurs in the range of $250-450{ }^{\circ} \mathrm{C}$. We found that solid-solid PCMs (ssPCMs) were successfully fabricated with the addition of 10 and $20 \mathrm{wt} \% \mathrm{q}-\mathrm{SiO} 2$. From DMA characterization, the BP/Q $20 \mathrm{wt} \%$ composite exhibited the maximum E' and the minimum energy dissipation (E"). Its E' value was approximately $250 \mathrm{MPa}$ more than that of the pure PEG. The glass transition (Tg) temperatures of PEG and BP/Q composites $(5,10$, and $20 \mathrm{wt} \%$ ) were around $-24.5,-19.1,-17.1$, and $-5.3{ }^{\circ} \mathrm{C}$, respectively. In addition, the E" and $\tan \delta$ values decreased with q-SiO2 filler content. Furthermore, the Cole-Cole plots of the BP/Q composites revealed a better interfacial bonding between the q-SiO2 and the PEG matrix in the composites with higher silica content. A compact morphology was shown by the BP/Q $20 \mathrm{wt} \%$ composite due to high silica concentration.
\end{abstract}

